\title{
SENTENCIA SOBRE RESPONSABILIDAD CIVIL DEL PROVEEDOR (CORTE DE APELACIONES DE CONCEPCIÓN)
}

\author{
Comentario de Erika Isler Soto
}

Concepción, 24 de diciembre de 2007

VISTOS:

Se reproduce la sentencia en alzada, a excepción del fundamento $7^{\circ}$ que se elimina y se tiene, además, presente:

1.- Que el abogado de la querellada interpone recurso de apelación en contra de la sentencia de primer grado fundado en que la acción deducida en su contra, se encontraba prescrita de acuerdo al artículo 26 inciso primero de la Ley $\mathrm{N}^{\circ} 19.496$, la que dispone expresamente que: "Las acciones que persigan la responsabilidad contravencional que se sanciona por la presente ley prescribirán en el plazo de seis meses, contados desde que se haya incurrido en la infracción respectiva". Argumenta también que le es agraviante, ya que la normativa sobre protección le es aplicable a los consumidores en la medida que exista la adquisición de un bien o la prestación de un servicio, todos ellos remunerados, indica que en la especie se está en presencia de un acto que no trajo como consecuencia la adquisición de un bien, sino que la existencia de un hecho comprendido bajo la responsabilidad extracontractual. Por ello es que el artículo 23 de la ley sanciona al proveedor que en la venta de un bien o en la prestación de un servicio, actos jurídicos que en la especie no se ha configurado por lo que mal se ha podido dar por establecida la infracción que da cuenta el considerando $3^{\circ}$ de la sentencia. Sostiene, además, que es agraviante por no existir conducta ilícita o culpable que habilite para otorgarla y por ser desmedida la cantidad otorgada por dicho concepto; y por último que es agraviante en cuanto impone el pago de reajuste desde la fecha de la ocurrencia del accidente hasta la del pago efectivo, en circunstancias que el derecho a obtener la indemnización de perjuicios viene a darse por establecido con la dictación de la sentencia. Pide en definitiva que se revoque la sentencia y se declare que se rechaza tanto la querella infraccional como la demanda civil, sea porque dichas acciones se encuentran prescritas, sea porque no se ha configurado infracción a la ley, o bien se rebaje sustancialmente el monto de la indemnización a favor del actor y la multa impuesta.

2.- Que es un hecho suficientemente acreditado como ha quedado establecido por el tribunal aquo, que el 23 de noviembre de 2003, aproximadamente a las 19:00 horas, 
don Emiliano Andrés Arias Madariaga concurrió al local de SODIMAC S.A., sucursal Talcahuano, con el objeto de adquirir diversos productos, y al momento de coger una lámpara de pie que había elegido, la que había sido conectada al tomacorriente por un vendedor, sufrió una descarga eléctrica que le provocó quemaduras en su mano derecha.

3.- Que, dos son las cuestiones fundamentales que se presentan a partir de estos hechos, la primera, consistente en que si la prescripción de la acción contravencional, ya resuelta, incluye la prescripción civil y, la segunda, si el hecho de que el consumidor no haya adquirido la mercadería a título oneroso lo deja al margen de la Ley de Protección del Consumidor.

4.- Que en lo que se refiere a la primera -prescripción civil-creemos en la subsistencia de la responsabilidad civil, una vez prescrita la responsabilidad infraccional que le sirve de sustento, del mismo modo que sobrevive a la extinción de la acción proveniente de un ilícito penal. Y no resulta aplicable a la acción civil porque el precepto del artículo 26 antes mencionado sólo se refiere a las acciones que persiguen la responsabilidad contravencional que se sanciona por la presente ley y a las sanciones impuestas en definitiva, pero no alude para nada a las acciones civiles, de que se trata el presente caso y cuya prescripción se gobierna por el derecho común. Lo contrario significaría aceptar que la Ley de Protección al Consumidor, fijó un plazo de prescripción especial para las acciones indemnizatorias de los consumidores de seis meses.

5.- Que, a mayor abundamiento, sostenemos que habiéndose incoado toda la tramitación en el procedimiento contemplado en la Ley de Protección del Consumidor con sentencia donde han quedado establecidos los hechos, la infracción debidamente tipificada, no resulta oportuno en estas circunstancias que la indemnización se solicite en un juicio en sede ordinaria, la economía procesal y los costos adversos para el consumidor para invocar la tutela jurisdiccional de sus derechos, la dilación que entraña la prosecución si se adoptara el procedimiento indicado, es que se debe estar al procedimiento contemplado por la ley de Protección al Consumidor, procedimiento sencillo y en teoría expedito ante los Juzgados de Policía Local, habilitando al consumidor para promoverlo y concentrando su tratamiento en la forma allí establecida, que ha sido por lo demás la constante que ha imperado en las últimas reformas legislativas, como la procesal penal, familia y del trabajo, donde se destacan los principios de inmediación, oralidad y concentración.

6.- Que, retomando el segundo punto en discusión, esto es, que el consumidor no adquirió la mercadería a título oneroso, por lo que quedaría al margen de la Ley de Protección del Consumidor. La ley indicada ha definido en su artículo $1^{\circ} \mathrm{N}^{\mathrm{o}} 1$ que se entiende por consumidores: las personas naturales o jurídicas que, en virtud de cualquier acto jurídico oneroso, adquieran, utilicen o disfruten, como destinatarios finales, bienes o servicios. 
7.- Que lo primero que se destaca, en el caso sub judice, es que no existió un acto jurídico oneroso, ello obedece a una simple explicación, esto es, que el consumidor quedó electrocutado al tomar la lámpara que pretendía adquirir y posteriormente derivado por sus lesiones a un centro asistencial. En estas condiciones, apreciando la prueba de acuerdo a las normas de la sana crítica, no le era exigible una conducta distinta a la adoptada, la lógica y la experiencia indican que lo esencial era la atención por las lesiones sufridas y el traslado a un hospital, como ocurrió, para el tratamiento de sus lesiones.

8.- Que como se ha sostenido por esta misma Corte, (Rol N $500-2005$, sentencia de 8 de noviembre de 2005) examinando la norma sobre protección de los derechos de los consumidores contenidos en la Ley $\mathrm{N}^{0}$ 19.496, de 7 de marzo de 1997 y las modificaciones introducidas por la Ley $\mathrm{N}^{\circ} 19.955$, se puede apreciar que la finalidad de estas reglas no es sólo desarrollar los aspectos de fondo que gobiernan las relaciones entre proveedores y consumidores, sino que además se contienen normas sobre el procedimiento aplicable en estas materias.

9.- Que como se advierte, el texto pretende entregar una normativa completa sobre las relaciones de consumo, esto es, tanto reglas sustantivas como procesales, relacionadas con el ejercicio de los derechos del consumidor. Así, este derecho del consumo no tiene como único fundamento la existencia de un vínculo jurídico previo ya que existen numerosas reglas que no tienen como supuesto la existencia de un contrato, como por ejemplo los artículos 13 y 15 de la ley mencionada los cuales imponen obligaciones al proveedor respecto del consumidor no contratante.

10.- Que otra disposición en este mismo sentido, es el artículo 12, contenido en el párrafo tercero sobre las obligaciones del proveedor, que dispone: "Todo proveedor de bienes o servicios estará obligado a respetar los términos, condiciones y modalidades conforme a las cuales se hubiere ofrecido o convenido con el consumidor la entrega del bien o la prestación del servicio".

11.- Que no hay aquí incumplimiento de una obligación contractual, o un acto jurídico oneroso, ya que la oferta es un paso previo a la celebración del contrato mismo, es decir, una responsabilidad precontractual, que nace a la vida del derecho antes de perfeccionarse el contrato que le servirá de fuente. En todos estos casos permite sostener que el concepto de consumidor que menciona el artículo $1^{\circ} \mathrm{N}^{\circ} 1$ de la Ley $\mathrm{N}^{\circ} 19.946$, no le es aplicable sólo a ese marco conceptual, sino que al demandante que como consumidor y habiendo sufrido una descarga eléctrica en el producto ofrecido no alcanzó ejecutar el acto jurídico oneroso.

12.- Que para la fijación del daño moral, que ha sido objeto de la apelación por las partes, esta Corte estima adecuado y prudente el determinado por el Juez de primer grado, atendido a la capacidad económica del demandado, la extensión del mal causado y finalmente las circunstancias particulares como acontecieron los hechos. 
13.- Que la suma por concepto de daño moral se pagará con reajustes calculados desde la fecha de la sentencia hasta su pago efectivo.

14.- Que habiéndose declarado prescrita la acción contravencional, el infractor no podrá ser objeto de condena en esta materia. Por estas consideraciones, disposiciones legales citadas y atendido además lo dispuesto en los artículos 32 y siguientes de la Ley $\mathrm{N}^{\mathrm{0}} 18.287$, se revoca la sentencia de treinta de diciembre de dos mil cuatro, escrita de fojas 48 a 49 vta. en cuanto se condena en la parte infraccional a SODIMAC S.A. representado por Marcelo Ruiz Vera al pago de una multa de treinta Unidades Tributarias Mensuales, y en su lugar se declara que queda absuelto por estar prescrita la acción contravencional. Se confirma en los demás la referida sentencia, con declaración, que la suma por concepto de daño moral se pagará con reajustes, calculados desde la fecha de la sentencia hasta su pago efectivo.

\section{Regístrese y devuélvase.}

Redacción del Ministro Jaime Simón Solís Pino.

No firma el Abogado Integrante don Patricio Mella Cabrera, no obstante haber concurrido a la vista y acuerdo de la causa, por estar ausente.

\section{COMENTARio}

Un primer tema tratado por la sentencia que se comenta, dice relación con la eventual exigencia de un contrato de consumo, como presupuesto obligatorio para la aplicación de la Ley $\mathrm{N}^{\circ} 19.496^{1}$, cuestión que ha sido ampliamente debatida.

En efecto, por una parte, se ha estimado que la LPC sólo resulta aplicable a aquellos casos en los cuales se haya celebrado un contrato de consumo entre las partes ${ }^{2}$, toda vez que el cobro efectivo de un precio o tarifa por parte del proveedor determinaría la existencia de una relación de consumo. Por consiguiente, si tal cobro tiene como causa correlativa la prestación a la que se obliga el proveedor, se sigue que la celebración de un acto de consumo es lo que determina la presencia de una relación de tal naturaleza.

La sentencia comentada - correctamente a mi juicio- adopta la posición contraria, esto es, estimar que la actual LPC no exige la celebración de convención alguna para su aplicación ${ }^{3}$. A mayor abundamiento, cabe señalar que la misma Ley regula situaciones que no exigen la concurrencia de un contrato, por lo que mal podría establecerlo como requisito de procedencia ${ }^{4}$.

\footnotetext{
${ }^{1}$ En adelante LPC, o simplemente la Ley.

2 En este sentido, Corte Suprema, Recurso de queja N N $^{\circ} 145-2008$, sentencia de fecha 21.10.08;

${ }^{3}$ Cfr. Considerandos 10 y 11, en el mismo sentido C.Ap. Concepción, Ing. 500-2005, 8.11.07.

${ }^{4}$ Así por ejemplo, Arts. 3, 13, 15, 18, 23, 28, 28A, 28B, 29, 30, 32, 33, 35, 36, 37 inc. 5, 43, 45,
} 46 LPC. 
De esta manera, es posible sostener que el estatuto contenido en la Ley $\mathrm{N}^{\circ} 19.496$, resulta aplicable a todo vínculo jurídico que tenga la naturaleza de relación de consumo, pudiendo esta última derivarse, tanto de un convención, como de una disposición del legislador. Esta última doctrina, es la seguida por la Corte de Apelaciones de Concepción en el fallo transcrito y es compatible además con la concepción moderna de consumidor, conforme a la cual, el sujeto activo de la protección no se encuentra constituido únicamente por el adquirente de bienes o servicios 5 .

Un segundo tema al que se refiere la sentencia en comento radica en determinar el plazo de prescripción aplicable a la responsabilidad civil del proveedor.

A este respecto, cabe recordar que el único artículo de la LPC que se refiere a la prescripción señala: "Las acciones que persigan la responsabilidad contravencional que se sanciona por la presente ley prescribirán en el plazo de seis meses, contado desde que se haya incurrido en la infracción respectiva ${ }^{6}$, pudiéndose concluir entonces que el legislador claramente silencia el plazo de la prescripción de las acciones civiles, lo que ha dado pie a otra ardua discusión jurídica.

Una primera corriente estima que la responsabilidad civil sólo nacerá si existe una condena infraccional previa ${ }^{7}$, puesto que la primera constituiría "una consecuencia inmediata $y$ directa de la responsabilidad contravencional" 8 . De esta manera, al no poder configurarse un supuesto autónomo de responsabilidad civil, necesariamente prescribiría ella, junto con la responsabilidad infraccional, es decir, en el plazo de seis meses, contados desde la infracción.

\footnotetext{
${ }^{5}$ En este sentido: Serrano Fernández, M.: "Daños materiales causados por un producto defectuoso", en Revista de Derecho Patrimonial, N 13, España, 2004, p. 282: "No existe un único concepto de consumidor (...). En términos generales, es posible distinguir una noción amplia de consumidor que incluiría a todos los ciudadanos (...) que aspiran a tener una adecuada calidad de vida. (...) Por su parte, la noción concreta de consumidor admite, a su vez, dos modalidades: La primera es aquélla que identifica consumidor con cliente, (...) siendo indiferente la finalidad perseguida por el sujeto al formar parte en la relación contractual; ( ) La segunda modalidad es la que identifica al consumidor con el destinatario final; de acuerdo con la misma para ser considerado consumidor es necesario no sólo que se adquieran bienes o servicios, sino que además se destinen éstos a un consumo privado".

${ }^{6}$ Art. 26 inc. $1^{\circ}$ LPC.

${ }^{7}$ Esta es la postura jurisprudencial mayoritaria, tal como se desprende de las siguientes sentencias: “Ovando con Abu Gosh”, Rol: 2972-2006, 2 JPL Punta Arenas, 26.07.06, considerando 3; "Garrido con Paris S.A.”, Rol 6682, 1 JPL Talcahuano, 03.10.08, considerando 3, revocada en este punto por la C. Ap. Concepción, ingreso 956-2008, 07.08.09; 1 JPL Pudahuel, Rol 5278-2006, 28.12.07, considerando 20, confirmada en este punto por la C. Ap. Santiago, Ing. 904-2008, 19.03.08; Rol 202-2006, 1 JPL Punta Arenas, 06.07.2006, confirmada por la C. Ap. Punta Arenas, 02.10.06, considerando 14; Rol 8306-2007, 1 JPL Viña del Mar, 25.02.08; "Canahuate con Sociedad Szerecz y Molina Ltda.”, Rol 5834-2007, 1 JPL Talcahuano, 26.09.08, considerando 6; "Cid con Isapre Consalud", Rol 259-2005, 1 JPL Osorno, considerando 11, confirmada por la C. Ap. Valdivia, ingreso 125-2006, 05.05.06.

${ }^{8}$ Así, "Muñoz con mueblería Peña y Morales”, Rol 5216-2008, 3 JPL Antofagasta, 26.08.08; "Menares con Almacenes Paris, Rol 3704-08, 3 JPL Antofagasta, 15.07.08; "Mujica con Castro”, Rol 3.788-2009, 3 JPL Antofagasta, 30.06.09, considerando 6; "Ehrenfehld con Hipermercado Lider Antofagasta”, rol 6656-2008, 3 JPL Antofagasta, 12.09.08, considerando 6; 29.863-2009, JPL Coyhaique, 18.08.09, considerando 4.
} 
Una segunda doctrina, la que considero correcta, estima que ambas formas de responsabilidad son independientes y poseen naturaleza diversa, por lo que ninguna de ellas sería presupuesto de la otra. Así, no se requeriría de la concurrencia de la responsabilidad infraccional para que operen las indemnizaciones correspondientes 9 .

Producto de lo anterior, es que la regla establecida en el Art. 26 LPC resultaría aplicable únicamente a la responsabilidad infraccional, rigiendo para las acciones civiles las reglas generales establecidas en el Derecho Común. Esta es la tesis que ha seguido la Corte de Apelaciones de Concepción en el caso que se comenta y se fundamenta además en que no resulta aceptable que la Ley de Protección al Consumidor establezca un plazo especial de prescripción ${ }^{10}$ menos beneficioso precisamente para el sujeto protegido por este estatuto. Producto de lo anterior, es que resulta totalmente procedente que la responsabilidad civil del proveedor subsista aún prescrita su responsabilidad infraccional, tal como ocurre en este caso concreto ${ }^{11}$.

9 En este sentido, "SERNAC y otro contra Agencia Eurotour Ltda.", Rol 102.921-MR $3^{\circ}$ JPL de Santiago, 02.02.1998, considerando 5.

${ }^{10} \mathrm{Cfr}$. Considerando 4.

${ }^{11}$ Cfr. Considerando 4. 